\title{
DEVELOPMENT OF THE PULSE MAGNETS FOR THE BOOSTER SYNCHROTRON OF SPRING-8
}

\author{
H.YONEHARA, H.SUZUKI, T.NAGAFUCHI*, M.KODAIRA*, T.AOKI, N.TANI, \\ S.HAYASHI, Y.UEYAMA, T.KANEDA, Y.SASAKI, H.ABE and H.Yokomizo \\ JAERI-RIKEN SPring-8 Project Team, Kamigori, Ako-gun, Hyogo 678-12 JAPAN \\ $*$ TOSHIBA co.,2-4, Suehiro-cyo, Tsurumi-ku, Yokohama 230, JAPAN
}

\begin{abstract}
Injection and extraction scheme of the SPring-8 synchrotron was designed. One kicker magnet, two septum magnets and one bump magnet which will be installed in the synchrotron to eject the electron beam of $8 \mathrm{GeV}$ were tested and successfully completed.
\end{abstract}

\section{INTRODUCTION}

The SPring-8 synchrotron is required that the synchrotron accepts the electron beam of $1 \mathrm{GeV}$ from the SPring- 8 linac, accelerates the beam energy upto $8 \mathrm{GeV}$ and ejects the electron beam to make stacking into the SPring- 8 storage ring with the repetition period of $1 \mathrm{~s}$. In multi-bunch mode-operation of the ring, the long-pulse electron-beam which has macro-bunch length of $1 \mu \mathrm{s}$ from the linac is accepted in half-number, continus buckets of the synchrotron. The beam train of $1 \mu \mathrm{s}$ is handled as a continuos beam in the synchrotron. In a single-bunch mode-operation, the synchrotron accepts the short-pulse beam which has macrobunch length less than $1 \mathrm{~ns}$ from the linac corresponding to one bucket length of the synchrotron. Moreover, the synchrotron is required to improve the beam current of the single-bunch modeoperation at the stacking of the ring. And 8 buckets of the synchrotron are occupied by the short-pulse beam from the linac and every spacings between the two buckets which are neighbor are the same length. And the electrons which occupy the 8 buckets are injected in a single bucket of the ring with contolling the time schedule of trigger signals for the electron gun of the linac and the pulse magnets of the injection and extraction systems of the synchrotron.

\section{INJECTION AND EXTRACTION SCHEMES}

\section{A. Injection Scheme}

Beam injection of the synchrotron was designed to be on-axis injection method. Injection system of the synchrotron is composed of two septum magnets and two kicker magnets. The injection scheme is shown in Fig. 1 and the aimed parameters of the magnets are shown in Table I. In this Table, the effective lengthes of the magnetic fields along the beam orbit are defined with the core lengthes. Leakage flux of the septum magnets on the injected beam is expected to enlarge the amplitude of the betatron oscillation. And allowance of the magnetic rigidity due to the leakage flux is estimated in order to suppress the betatron enlargement less than $1 \mathrm{~mm}$ at $\mathrm{Si} 2$ where the physical aperture of the synchrotron is the minimum size. Apertures of the magnets are to be so large that the beam passes through the magnetic

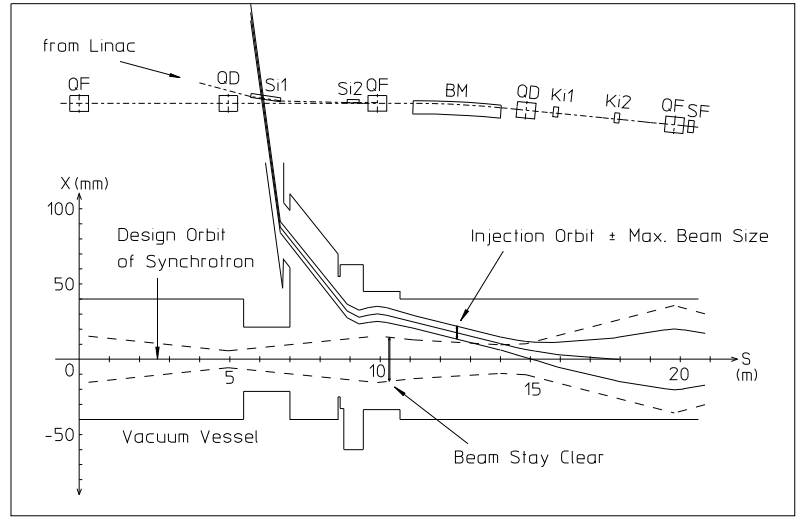

Figure 1. Beam Injection Scheme (Horizontal) - Solid line shows horizontal beam size on injection line from the linac and broken line shows beam-stay-clear of the injected beam.

Table I

Design Parameters of Pulse Magnets - Allowance of leakage shows field strengths on the designed orbit in the case of the injection magnets, and on the bump orbit in those of the extraction magnets.

\begin{tabular}{|c|c|c|c|}
\hline $\begin{array}{c}\text { Pulse } \\
\text { Magnets }\end{array}$ & $\begin{array}{c}\text { Mag. Field } \\
\text { Strength(T) }\end{array}$ & $\begin{array}{c}\text { Effective } \\
\text { Length(m) }\end{array}$ & $\begin{array}{c}\text { Allowance of } \\
\text { Leakage(Tm) }\end{array}$ \\
\hline Si1 & 0.789 & 0.987 & $3.3 \times 10^{-4}$ \\
\hline $\mathrm{Si} 2$ & 0.250 & 0.400 & $1.9 \times 10^{-4}$ \\
\hline $\mathrm{Ki}$ & 0.0264 & 0.200 & - \\
\hline $\mathrm{Bp} 1$ & 0.112 & 0.170 & - \\
\hline $\mathrm{Bp} 2$ & 0.159 & 0.170 & - \\
\hline $\mathrm{Bp} 3$ & 0.0966 & 0.170 & - \\
\hline $\mathrm{Bp} 4$ & 0.156 & 0.170 & - \\
\hline $\mathrm{Ke}$ & 0.0395 & 0.400 & - \\
\hline $\mathrm{Se} 1$ & 0.263 & 0.200 & $1.2 \times 10^{-3}$ \\
\hline $\mathrm{Se} 2$ & 0.257 & 0.400 & $1.2 \times 10^{-3}$ \\
\hline $\mathrm{Se} 3$ & 0.970 & 1.110 & $2.1 \times 10^{-3}$ \\
\hline $\mathrm{Se} 4$ & 1.152 & 1.400 & $1.1 \times 10^{-3}$ \\
\hline
\end{tabular}

field and the beam size is given in Table II with the positronbeam parameters of the linac. Beam size at the beam injection and the closed orbit distortion(COD) before COD correction are estimated by using "RACETRACK" with the electron-beam parameters of the linac and the beam-stay-clear shown in Table II.

\section{B. Extraction Scheme}

Extraction system of the synchrotron consists of three kicker magnets, four septum magnets and four bump magnets, which are used to extract the electron beam with $8 \mathrm{GeV}$ from the synchrotron. The extraction scheme is shown in Fig. 2. The aimed parameters of the magnet are shown in Table I and the beam 
Table II

Beam Size and BSC at Injection

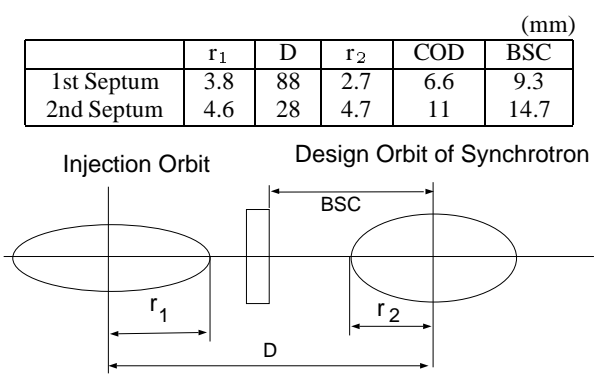

Table III

Beam Size at Extraction

\begin{tabular}{|c|c|c|c|}
\multicolumn{1}{|c}{} & $(\mathrm{mm})$ \\
\hline & $\mathrm{r}_{1}(2.5 \sigma)$ & $\mathrm{D}$ & $r_{2}(3 \sigma)$ \\
1st Septum & 4.4 & 19 & 5.2 \\
2nd Septum & 4.5 & 22 & 5.0 \\
3rd Septum & 2.1 & 36 & 2.5 \\
4th Septum & 3.0 & 91 & 3.6 \\
\hline
\end{tabular}

Extraction Orbit Bump Orbit of Synchrotron

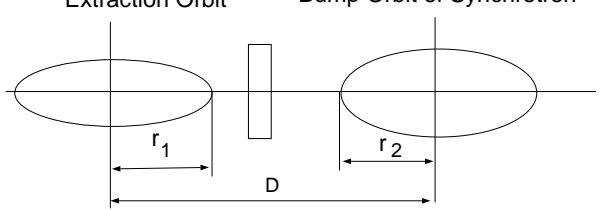

size is given in Table III with the parameters of the synchrotron. Leakage flux of the septum magnet on the bump orbit is expected to enlarge the amplitude of the betatron oscillation, and allowance of the magnetic rigidity due to the leakage flux is estimated to suppress the betatron enlargement less than $0.4 \mathrm{~mm}$ at Se1 where the horizontal spacing between the bump orbit and the septum plates is the narrowest size. The performances of two septum, one kicker and one bump magnets, which will be installed in the extraction system, were tested and successfully completed.

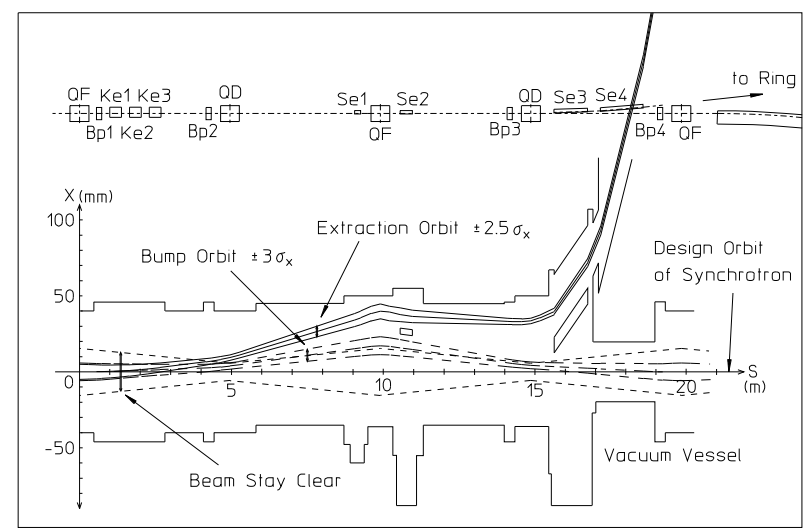

Figure 2. Beam Extraction Scheme (Horizontal) - Solid line shows horizontal beam size on extraction line from the synchrotron and broken line and dotted line show bump orbit and beam-stay-clear of the injected beam.

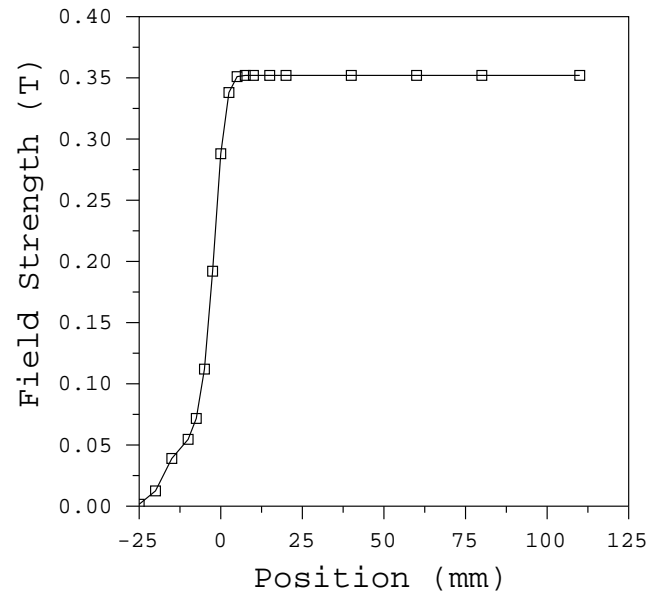

Figure 3. Magnetic-Field Distribution of $\mathrm{Se} 2$ at the Upstream End - The position of $\mathrm{s}=0 \mathrm{~mm}$ shows the core end of $\mathrm{Se} 2$.

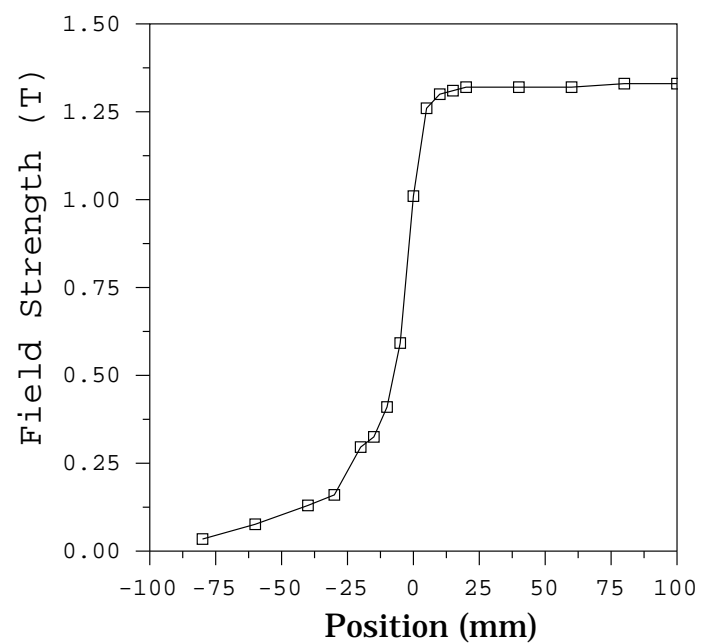

Figure 4. Magnetic-Field Distribution of $\mathrm{Se} 3$ at the Upstream End - The position of $\mathrm{s}=0 \mathrm{~mm}$ shows the core end of Se3.

\section{PULSE MAGNETS}

\section{A. 2nd Septum Magnet of Extraction System}

Magnetic-field strength of the 2nd septum magnet was measured. The field distribution on the extraction orbit at the magnet end is shown in Fig.3. The effective length of the field is $9 \mathrm{~mm}$ longer than the core length, and the magnetic rigidity of $3.4 \times 10-5 \mathrm{Tm}$ due to the leakage flux is smaller than the leakage allowance of $1.2 \times 10-3 \mathrm{Tm}$.

\section{B. 3rd Septum Magnet of Extraction System}

Magnetic-field strength of the 3rd septum magnet was measured. The field distribution on the extraction orbit at the magnet end is shown in Fig. 4. The effective length of the field is $20 \mathrm{~mm}$ longer than the core length, and the magnetic rigidity of $1.1 \times 10-3 \mathrm{Tm}$ due to the leakage flux is smaller than the leakage allowance of 2.1x10-3 Tm.

\section{Kicker Magnet of Extraction System}

In order to achieve the single-bunch mode-operation of the storage ring, rise time and fall time of the magnetic field have 


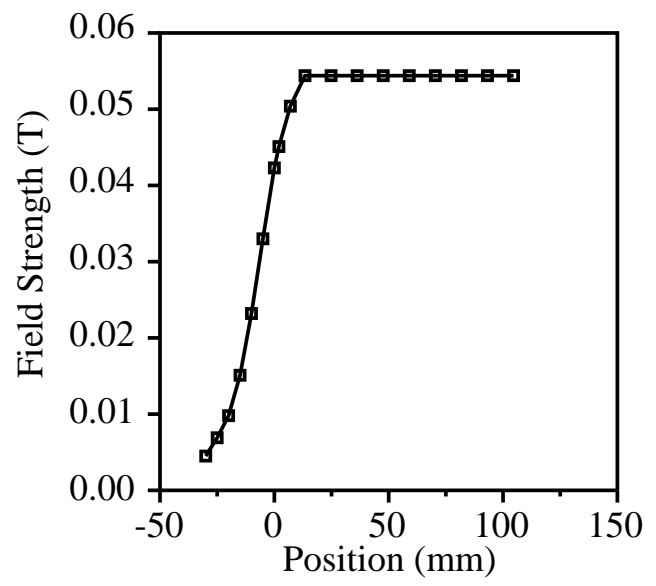

Figure 5. Magnetic-Field Distribution of Ke1 - The position of $\mathrm{s}=0 \mathrm{~mm}$ shows the pole end of $\mathrm{Ke} 1$.

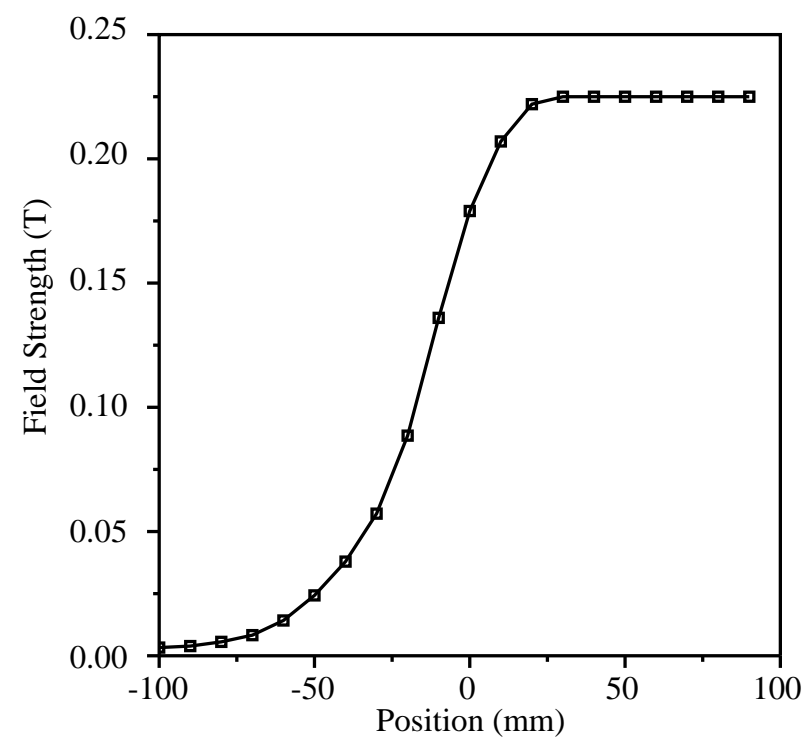

Figure 6. Magnetic-Field Distribution of Bp2 at the Downstream End - The position of $\mathrm{s}=0 \mathrm{~mm}$ shows the core end of Bp2.

to be shorter than $50 \mathrm{~ns}$ and $150 \mathrm{~ns}$, respectively. The flat-top time is required to be longer than $60 \mathrm{~ns}$. Trial manufacture of the kicker magnet was completed successfuly. ${ }^{1)}$ The field distribution of Ke1 along the design orbit is shown in Fig. 5. The effective length is $18 \mathrm{~mm}$ longer than the pole length, and the waveform of the magnetic field is gratified.

\section{Bump Magnet of Extraction System}

The waveform of the kicker magnet at the beam extraction must be very fast. It is difficult to get strong magnetic-flux density and make long pole length of the kicker. The bump orbit is formed with four bump magnets and the extraction orbit is achieved on the bump orbit beause of the low magnetic-rigidity of the fast kicker. The field distribution of $\mathrm{Bp} 2$ along the design orbit is shown in Fig. 6 and the effective length is $36 \mathrm{~mm}$ longer than the core length of the magnet.

\section{CONCLUSION}

In the synchrotron, fifteen pulse magnets are installed to inject and eject electron beam. Some magnets which had been considered to have some difficulties in manufacturing have been constructed in an early stage of the synchrotron-construction plan. These magnets and the power supplies were completed successfully. We have started to manufacture the remainders of the pulse magnets on schedule.

\section{ACKNOWLEDGEMENT}

The authors are thankful to computer control group of the SPring-8 injector team for their supporting DTP and CAD of this article.

\section{REFERENCE}

1) Y. Sasaki, H. Yonehara, H. Suzuki and T. Aoki; Proceedings of the 9th Symposium on Accelerator Science and Technology, Tsukuba, Japan p.255, 1993.@ 